\title{
Use of Intraoperative Analgesic and Anesthetic Substances by Intramuscular Infiltrations during Hip Surgery for Postoperative Pain Monitoring
}

\author{
BOGDAN HOGEA ${ }^{1}$, BOGDAN CORNELIU ANDOR ${ }^{1 *}$, ALINA TOTOREAN ${ }^{2 *}$, LAVINIA MARIA HOGEA ${ }^{1}$, \\ LAURA ALEXANDRA NUSSBAUM ${ }^{1}$, ANCA BISTRIAN ${ }^{1}$, MIHAI ALEXANDRU SANDESC ${ }^{1}$, ROXANA FOLESCU ${ }^{1}$, \\ MARIA CORINA STANCIULESCU ${ }^{1}$, ROMEO PETRU DOBRIN ${ }^{3 *}$, MIHAELA BOANCA ${ }^{3}$, JENEL MARIAN PATRASCU J $r^{1}{ }^{1}$ \\ ${ }^{1}$ Victor Babes University of Medicine and Pharmacy, 2 Eftimie Murgu Sq., 300041 Timi'oara, Romania \\ ${ }^{2}$ County Emergency Clinical Hospital Pius Brinzeu Timisoara IInd Orthopedics and Traumatology Clinic, 2 Eftimie Murgu Sq., \\ 300041 Timisoara, Romania \\ ${ }^{3}$ Grigore T. Popa University of Medicine and Pharmacy, 16 Universitatii St., 700115 lasi, Romania
}

\begin{abstract}
The authors present their intraoperative and postoperative experience in using intramuscular infiltrations with analgesic and anesthetic substances as pain control methods in patients that undergo hip surgery: arthroplasty or hemiarthroplasty. A total of 30 patients that have undergone either an elective total hip arthroplasty surgery or hemiarthroplasty of the hip following a hip fracture, since May 2018 until August 2018. The patients were divided in two equal groups, one group that followed through the protocol and one control group. The intramuscularinfiltrations were administered intraoperativelyat the timeline of the muscle suture and contained: Bupivacaine $10 \mathrm{~mL}+$ Morphine $1 \mathrm{~mL}+$ Methylprednisolone 40mg. Postoperative protocol used the visual analogue scale (VAS) pain scores on days 1, 2, 3, 4, 5, 6 and 7 for measuring the postoperative pain control. Intraoperative intramuscular infiltrations, with an analgesic and anesthetic cocktail consisting of Bupivacaine, Morphine and Methylprednisolone, for patients that are going through hip surgery are safe to use with very good results in terms of postoperative pain control. We reduced the consumption of opioids and analgesic drugs, which indirectly leads to decreased direct cost per patient. Another important benefit was an earlyactive mobilization of the patient, with shorter hospitalization time. All things considered, using regional anesthesia and multimodal pain management techniques may lead to a nearly painless hip surgery.
\end{abstract}

Keywords: intramuscular, infiltrations, pain, hip arthroplasty, substances

It is well known that hip arthritis and femoral head fractures are severe, painful and sometimes debilitating pathologies with positive outcome after total or partial arthroplasty of the hip. In order to minimize the postoperative pain, to increase patient's compliance in terms of active postoperative mobilization and shorten the hospitalization period, we decided to use intramuscular infiltrations of analgesic and anesthetic substances, intraoperatively $[1,2]$.

Bupivacaine is an amino-amide anesthetic (fig. 1); the aromatic head and the hydrocarbon chain are linked by an amide bond rather than an ester as in earlier local anesthetics. As a result, the amino-amide anesthetics are more stable and less likely to cause allergic reactions. Unlike lidocaine, the terminal amino portion of bupivacaine (as well as mepivacaine, ropivacaine, and levobupivacaine) is contained within a piperidine ring; these agents are known as pipecholyl xylidines. The rate of systemic absorption of bupivacaine is dependent upon the dose and concentration of drug administered the route of administration, the vascularity of the administration site, and the presence or absence of epinephrine in the preparation. Onset of action (route and dose-dependent): 1-17 min and duration of action (route and dosedependent): $2-9 \mathrm{~h}[3,4]$.

Methylprednisolone is a synthetic corticosteroid with anti-inflammatory and immunomodulation properties (fig. 2). Methylprednisolone binds to and activates specific nuclear receptors, resulting in altered gene expression and inhibition of proinflammatory cytokine production.

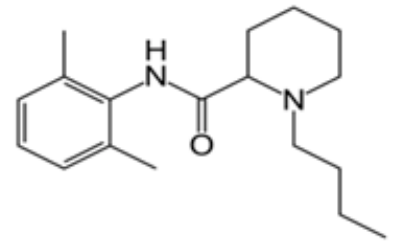

Fig.1. Chemical formula for Bupivacaine- $\mathrm{C}_{18} \mathrm{H}_{28} \mathrm{~N}_{2} \mathrm{O}$

Unbound glucocorticoids cross cell membranes and bind with high affinity to specific cytoplasmic receptors, modifying transcription and protein synthesis. By this mechanism, glucocorticoids can inhibit leukocyte infiltration at the site of inflammation, interfere with mediators of inflammatory response, and suppress humoral immune responses. The anti-inflammatory actions of corticosteroids are thought to involve phospholipase A2 inhibitory proteins, lipocortins, which control the biosynthesis of potent mediators of inflammation such as prostaglandins and leukotrienes. The average plasma methylprednisolone concentration was approximately $20 \%$ higher after the intramuscular administration of methylprednisolone sodium phosphate [5].

Morphine is metabolized primarily in the liver and approximately $87 \%$ of a dose of morphine is excreted in the urine within $72 \mathrm{~h}$ of administration (fig. 3). Resultant plasma levels after subcutaneous (SC), intramuscular (IM), and IV injection are all comparable. After IM or SC injections, morphine plasma levels peak in approximately $20 \mathrm{~min}$, and, after oral administration, levels peak in approximately $30 \mathrm{~min}$. Morphine is metabolized primarily 

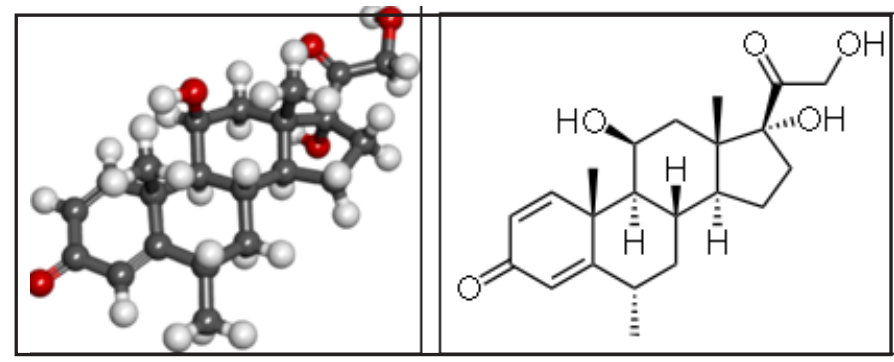

Fig. 2. Chemical formulas for Methylprednisolone $-\mathrm{C}_{22} \mathrm{H}_{30} \mathrm{O}_{5}$ into morphine-3-glucuronide (M3G) and morphine-6glucuronide (M6G) via glucuronidation by phase II metabolism enzyme UDP-glucuronosyl transferase2B7(UGT2B7). About $60 \%$ of morphine is converted to M3G, and $6 \%$ to $10 \%$ is converted to M6G. Metabolism rate is determined by gender, age, diet, genetic makeup, disease state (if any), and use of other medications. The elimination half-life of morphine is approximately $120 \mathrm{~min}$, though there may be slight differences between men and women. Morphine can be stored in fat, and, thus, can be detectable even after death. Morphine can cross the blood-brain barrier, but, because of poor lipid solubility, protein binding, rapid conjugation with glucuronic acid and ionization, it does not cross easily [3, 4].

The steroid prevents local inflammation, and morphine stimulates all three opiate receptors ( $\mu, \delta$, and $k$ ) in the joint with less adverse systemic effects.

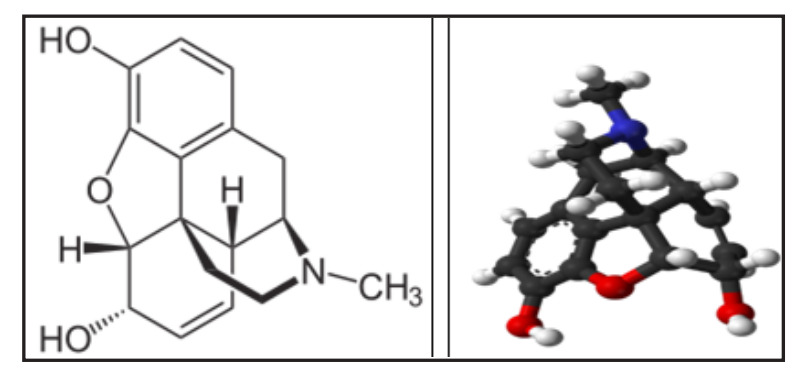

Fig. 3. Chemical formula for Morphine $-\mathrm{C}_{17} \mathrm{H}_{19} \mathrm{NO}_{3}$

This paper presents the data regarding using intraoperative and postoperative by intramuscular infiltrations with analgesic and anesthetic substances as pain control methods in patients that undergo hip surgery: arthroplasty or hemiarthroplasty.

\section{Experimental part}

In our clinic, we use either the direct antero-lateral approach (Watson J ones) or the posterior approach for the treatment of hip fractures.

A total of 30 patients, ranging in age from 50 to 86 years old, that have had an elective total hip arthroplasty or hemiarthroplasty of the hip following a hip fracture, since May 2018 until August 2018. We performed hemiarthroplasties for 19 patients with femoral neck fractures, and on 11 patients, THA was performed, for either femoral neck fracture or hip arthritis.

The patients, 20 females and 10 males, were divided in 2 equal groups, and Group A that included 15 patients, was the group in which near the end of the surgery, patients received intramuscular infiltrations with Bupivacaine $10 \mathrm{~mL}+$ Morphine $1 \mathrm{~mL}$ + Methylprednisolone $40 \mathrm{mg}$. A total of 15 patients submitted an informed consent that was written specifically for this study group. Group B, that also included 15 patients, was the control group in which the patients didn'treceive intramuscular infiltrations. The study was conducted in accordance to the Helsinki Declaration and to some published models [6-8]. The visual analogue scale (VAS) pain scores on days 1, 2, 3, 4, 5, 6 and 7 post-surgery was used for measuring the postoperative pain control $[9,10]$.

In our study, we used the numerical VAS score as it has more feasibility and better compliance. The Visual Analogue Scale (VAS) consists of a straight line with the endpoints defining extreme limits such as no pain at all and pain as bad as it could be. The patient is asked to mark his pain level on the line between the two endpoints. The distance between no pain at all and the mark then defines the subject's pain. This tool was first used in psychology by Freyd in 1923. If descriptive terms like mild, moderate, severe or a numerical scale is added to the VAS [9]. In a Numerical Rating Scale (NRS), patients are asked to circle the number between 0 and 10 that fits best to their pain intensity. Zero usually represents no pain at all whereas the upper limit represents the worst pain ever possible. In contrast to the VAS, only the numbers themselves are valuable answers, meaning that there are only 11 possible answers in a 0-10. The following postoperative parameters were analyzed: postoperative pain using the VAS score, local healing evolution, the presence or absence of adverse reactions and hospitalization time [9, 11-14]. The visual analogue scale (VAS) pain scores on days 1, 2, 3, 4, 5, 6 and 7 after surgery was used for measuring postoperative pain control.

\section{Results and discussions}

In figure 4 is represented the mean of postoperative VAS pain score was lower in group $A=4$ (mild pain) compared to group $B$ that had a score of 7.5 (intense pain).

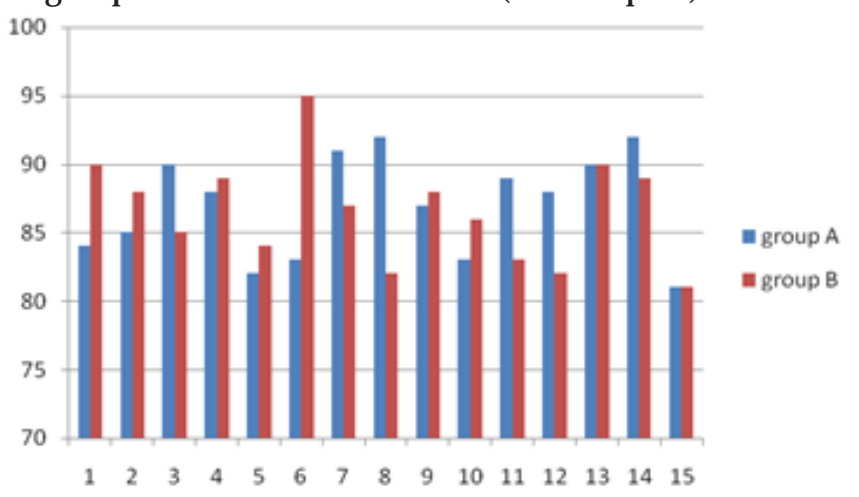

Fig. 4. Preoperative VAS values in both groups

Significant difference, as seen in figure 5, was observed on days two and three post surgery in the group of patients who received the injection.

Patients in the hip study group had lower pain scores and better satisfaction on each day of hospitalization. Furthermore, the overall painkiller consumption was lower in group $A$.

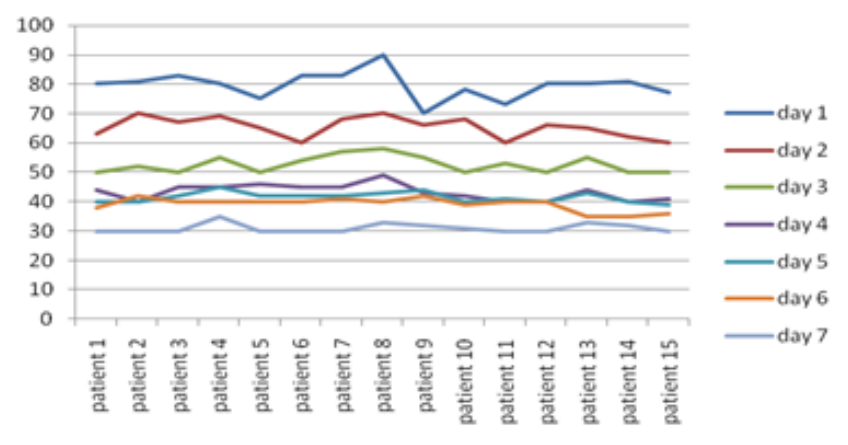

Fig. 5. Postoperative tendencies in group A during 7 days 
Earlier active mobilization of the patients and shorter hospitalization period were also seen in group $\mathrm{A}$. More patients in the study group (48\%) were able to do active straight leg raise on postoperative day 1 . Mean hospitalization time was 7.5 days compared to group B that had almost double hospitalization time: 12 to 14 days [15-19].

At discharge, the patient's goal is to walk independently with support for at least 15-20 meters and transferring independently in and out of bed and toilet.

Regarding the study group we reported no local complications or adverse effects.

All patients had access to physiotherapy after discharge: either with a physical therapist in their homes or in a rehabilitation facility [20]. The patients are instructed to walk daily, gradually increasing the distance. Also, we advise to walk without a walking stick for short walks for 6-8 weeks, and to use a walking stick for 2 more weeks, but only for long walks [21, 22].

\section{Conclusions}

Intraoperative intramuscular infiltrations, using an analgesic and anesthetic cocktail, made of Bupivacaine, Morphine and Methylprednisolone, for patients that are undergoing hip surgery using antero-lateral approach, are safe to use with very good results. It is important to highlight the obvious trend of simultaneous improvement in VAS scale.

In terms of postoperative pain control, we achieved a lower consume of opioids and painkillers, that led to decreased direct cost per patient.

Another important benefit was an earlier active mobilization of the patient and shorter hospitalization time.

The use of regional anesthesia and multimodal pain management techniques may lead to a nearly painless hip surgery. Patients have greater satisfaction with their operation when they avoid complications that could be caused by systemic drugs.

The multimodal approach of pain management reduces some serious complications such as respiratory depression, nausea, vomiting, hypotension, bradycardia, and cognitive altering.

We consider that a multimodal pain program with periarticular injection brings a substantial advance in perioperative pain assessment after THA. Even though our study was conducted on a small group of patients, our results are promising; therefore, future studies on larger groups of patients, in order to prevent biases, are needed.

\section{References}

1.HAEFELI, M., ELFERING, A., Eur. Spine. J., 15, Suppl. 1, 2006, p. 17. 2.PARDO, M., MILLER, R.D., Basics of Anesthesia, 7th Edition, Elsevier, 2017.

3.*** Bupivacaine hydrochloride (Bupivacaine Hydrochloride) injection, solution \& quot; FDA. https://www.accessdata.fda.gov/ drugsatfda_docs/label/2015/018053s055lbl.pdf
4.***, Bupivacaine Injection: https://www.ashp.org/drug-shortages/ current-shortages/Drug-Shortage-Detail.aspx?id $=172$

$5 . * * *$, Methylprednisolone, The American Society of Health-System Pharmacists, 2016.

6.POROCH, V., AGHEORGHIESEI, D.T., Postmodern Openings, 9, no. 2, 2018, p. 225.

7.ROGOZEA, L., REPANOVICI, A., CRISTEA, L., BARITZ, M., MICLAUS, R., PASCU, A., Proceedings of the 4th WSEAS/IASME International Conference on Educational Technologies (Edute'08), Book Series: Recent Advances in Computer Engineering, Corfu, Greece, 2008, Oct. 26-28, p. 87.

8.AGHEORGHIESEI CORODEANU, D.T., POROCH, V., 6th LUMEN International Conference on Rethinking Social Action Core Values, 16-19 April 2015, lasi, Romania, Rethinking Social Action. Core Values, p. 33.

9.TRESCOT, A.M., DATTA, S., LEE, M., HANSEN, H., Pain Physician, 11, Suppl. 2, 2008, p. 133.

10.HOGEA, L.M., HOGEA, G.B., NUSSBAUM, L.A., GRIGORAS, M.L., ANDOR, B.C., LEVAI, C.M., BREDICEAN, A.C., Rom. J. Morphol. Embryol, 58, no 1, 2017, p. 175

11.NUSSBAUM, L.A., HOGEA, L.M., FOLESCU, R., GRIGORAS, M.L., ZAMFIR, C.L., BOANCA, M., ERDELEAN, D., ROSCA, E.C.I., NUSSBAUM, L.M., SIMU, M.A., LUPU, V., Rev. Chim.(Bucharest), 69, no. 4, 2018, p. 965.

12.AGEU, L.S., LEVAI, C.M. ANDREESCU, N.I., GRIGORAS, M.L., HOGEA, L.M., CHIRIAC, D.V., FOLESCU, R., BREDICEAN, A.C., NUSSBAUM, L.M., ENATESCU, V.R., POROCH, V., LUPU, V., PUIU, M., NUSSBAUM, L.A., Rom. J. Morphol. Embryol, 59, no. 1, 2018, p. 165.

13.NUSSBAUM, L.A., HOGEA, L.M., CHIRIAC, D.V., GRIGORAS, M.L., FOLESCU, R., BREDICEAN, A.C., ROSCA, E.C.I., MUNCAN, B., NUSSBAUM, L.M., SIMU, M.A., LEVAI, C.M., Rom. J. Morphol. Embryol, 58, no. 4, 2017, p. 1435.

14.BOANCA, M., MITITELU-TARTAU, L., LUPUSORU, L.V., POROCH, V., BIBIRE, N., LUPUSORU, C.E., Farmacia, 63, no. 3, 2015, p. 362.

15.DORP, E.L., ROMBERG, R., SARTON, E., BOVILL, J.G., DAHAN, A., Anesthesia and Analgesia, 102, no. 6, 2006, 1789.

16.KILPATRICK, G.J ., SMITH, T.W., Medicinal Research Reviews, 25, no. 5, 2005, p. 521.

17.NOVAK, E., DISANTO, A.R., SECKMAN, C.E., ELLIOTT, G., LEE, J .G., STUBBS, S.S., J. Clin. Pharmacol., 17, no. 5, 1977, p. 324.

18.CHIRIAC, D.V., HOGEA, L.M., BREDICEAN, A.C., REDNIC, R., NUSSBAUM, L.A., HOGEA, G.B., GRIGORAS, M.L., Rom. J. Morphol. Embryol, 58, no. 3, p. 1023.

19.MOSOIU, D., SPORIS, M., STANCULEANU, D. L., TOADER, E., POROCH, V., BOANCA, M., SIMION, L., Rev. Chim.(Bucharest), 68, no. 5, 2017, p. 1051.

20.KARCH, S.B., (editor), Pharmacokinetics and Pharmacodynamics of Abused Drugs, 1st Edition, CRC Press, 2007.

21.HOGEA, L.M.,TUTASAS, I., POROCH, V., NUSSBAUM, L.A., SAS, I., SERBAN, D., ERDELEAN, D., FOLESCU, R., ZAMFIR, C.L., BREDICEAN, C.A., SIMU, M.A., Rev. Chim.(Bucharest), 69, no. 4, 2018, p. 934

22.HOGEA, L.M., NUSSBAUM, L.A., CHIRIAC, D.V., AGEU, L.S., ANDREESCU, N.I., GRIGORAS, M.L., FOLESCU, R., BREDICEAN, A.C., PUIU, M., ROSCA, E.C.I., SIMU, M.A., LEVAI, C.M., Rom. J. Morphol.Embryol, 58, no. 3, 2017, p. 767.

Manuscript received: 6.08 .2018 